\title{
Number-of-features effects and semantic processing
}

\author{
PENNY M. PEXMAN, GREGORY G. HOLYK, and MARIE-H. MONFILS \\ University of Calgary, Calgary, Alberta, Canada
}

\begin{abstract}
Participants list many semantic features for some concrete nouns (e.g., lion) and fewer for others (e.g., lime; McRae, de Sa, \& Seidenberg, 1997). Pexman, Lupker, and Hino (2002) reported faster lexical decision and naming responses for high number of features (NOF) words than for low-NOF words. In the present research, we investigated the impact of NOF on semantic processing. We observed NOF effects in a self-paced reading task when prior context was not congruent with the target word (Experiment 1) and in a semantic categorization task (concrete vs. abstract; Experiment 2A). When we narrowed our stimuli to include high- and low-NOF words from a single category (birds), we found substantial NOF effects that were modulated by the specificity of the categorization task (Experiments 3A, 3B, and $3 \mathrm{C}$ ). We argue that these results provide support for distributed representation of word meaning.
\end{abstract}

There is little debate in the psycholinguistic literature that single-word reading involves activation of orthographic, phonological, and semantic information. Models of visual word recognition differ, however, in their assumptions about how these different types of knowledge interact and how the information is represented. The focus of the present research is the issue of how word meanings are represented.

\section{Models of Word Meaning}

Classical lexical models assume a system of local representation, in which each word is represented by a single unit at the lexical level and by a single unit at the semantic (meaning) level (e.g., Becker, 1980; Forster, 1976; Morton, 1969; Paap, Newsome, McDonald, \& Schvaneveldt, 1982). When a word is read, an orthographic representation is constructed, and this guides selection of a lexical unit. Next, a semantic unit is selected. Balota, Ferraro, and Connor (1991) revised the classical models somewhat to include interactive activation (McClelland \& Rumelhart, 1981) between the lexical and the semantic units and the possibility that, for some words, a single lexical unit could be linked to multiple semantic units (i.e., for ambiguous words, such as bank). Note, however, that local representation was still assumed, so that each semantic unit corresponded to a particular word meaning. This type of repre-

Portions of the research described in this article were presented at the 42nd Annual Meeting of the Psychonomic Society, Orlando, FL, November 2001. This research was supported in part by a grant to P.M.P. and postgraduate scholarships to G.G.H. and M.-H.M., all from the Natural Sciences and Engineering Research Council of Canada. The authors thank Ken McRae for providing the feature norms, Jodi Edwards for testing participants, and Art Glenberg, Greg B. Simpson, Mark Yates, and Ken McRae for providing very helpful comments on an earlier version of the manuscript. Correspondence concerning this article should be addressed to P. M. Pexman, Department of Psychology, University of Calgary, 2500 University Drive NW, Calgary, AB, T2N 1N4 Canada (e-mail: pexman@ucalgary.ca). sentation system, in which one node represents one concept, was also instantiated in early models of conceptual memory (e.g., Anderson, 1983; Collins \& Loftus, 1975).

In contrast, a system of distributed representation was incorporated in later models of word recognition (e.g., Borowsky \& Masson, 1996; Kawamoto, 1993; Masson, 1995; Plaut, 1997; Plaut, McClelland, Seidenberg, \& Patterson, 1996; Seidenberg \& McClelland, 1989; Van Orden, Pennington, \& Stone, 1990). In these models, word meaning is captured by patterns of activation across meaning units. Meaning units do not correspond to specific concepts. For instance, Masson's distributed memory model involves three processing modules: orthographic units, phonological units, and meaning units. In this respect, Masson's model is similar to connectionist models of the type proposed by Seidenberg and McClelland. One key difference is that Masson implemented the semantic units, whereas Seidenberg and McClelland implemented only the orthographic and the phonologicalunits. Masson's model was simulated as a Hopfield network, so that all the units in the model are connected to each other. Masson's model is neutral with respect to what the semantic units represent. That is, it is suggested that the semantic units correspond to semantic features of some kind, but no claims are made about the nature of those features. Similarly, Kawamoto's model is a fully recurrent (completely interconnected) network, and meaning units were assigned semantic features (primitives) in a fairly arbitrary way. Importantly, these models, which involve distributed representation schemes, have been quite successful in simulating certain aspects of visual word recognition performance (cf. Forster, 1994).

McRae, de Sa, and Seidenberg (1997) proposed a connectionist model of word meaning involving featural representations (see also Hinton \& Shallice, 1991). That is, each meaning unit in the model represents a particular semantic feature (e.g., has fur). The model is an attractor network. As such, a correlational learning algorithm was used to 
code covariations among features. When a word is presented, there is, initially, activation of a pattern in the meaning units that roughly approximates the word's meaning. This pattern of activation falls within the word's basin of attraction in semantic space and, over processing cycles, settles further into the basin of attraction until a stable state is achieved. Settling is facilitated by knowledge of feature correlations.

In simulating this model, McRae et al. (1997) first collected a set of empirically derived norms. Participants were asked to list features for each word in a large set of basiclevel concepts. Features were included for a given concept in the norms if they were listed by at least 5 of 30 participants. The features listed tended to include perceptual information (e.g., has feathers), categorical information (e.g., is a bird), and information about the way humans interact with the referent (e.g., is nutritious and has starch for the word potato). Some concepts produced many features and some produced fewer features. As was expected, some features often occurred together (were correlated; e.g., has feathers and has a beak), whereas others never occurred together (e.g., is purple and has a beak). Behavioral experiments demonstrated the influence of correlations among features on, for instance, semantic priming effects. That is, stronger priming was observed when words within a related pair shared features. Thus, correlated features influenced the speed with which word meaning was computed.

McRae et al. (1997) concluded that featural representations are used in the initial computation of word meaning and, therefore, will affect performance in speeded semantic tasks. The authors acknowledged that higher level knowledge is also relevant to semantic processing (e.g., Medin, 1989) but argued that the effects of such knowledge would be apparent in different sorts of tasks (e.g., untimed reasoning tasks). The suggestion is that concepts are much more than just sets of features but that, at least early on in processing, featural representations are important to the computation of word meaning.

\section{The Number-of-Features Effect}

Recently, Pexman, Lupker, and Hino (2002) reported that words with many semantic features were responded to more quickly than words with fewer semantic features in a lexical decision task (LDT) and also in a naming task. They referred to these differences as number-of-features (NOF) effects. The words used in these experiments were taken from McRae et al.'s (1997) norms and were selected so that, for half of the words, the participants in McRae et al.'s study had listed many features (e.g., lion) and, for the other half of the words, the participants in McRae et al.'s study had listed significantly fewer features (e.g., lime).

The main objective of Pexman et al.'s (2002) study was to test the notion of semantic feedback activation. Many models of word recognition assume bidirectional activation between sets of processing units. As such, the assumption is that there is both feedforward and feedback activation between, for instance, orthographic and semantic units. Since the focus of the present article is not the feedback activation idea, we will not describe it in detail here. In brief, the purpose of Pexman et al.'s (2002) study was to test the claim that words that produce relatively more semantic activation would produce more semantic feedback activation to the orthographic and phonological units and, therefore, should show a processing benefit in the LDT and also in naming tasks (for explanations of why LDT and naming task performance is argued to be sensitive to semantic feedback activation, and not just to semantic activation per se, see Hino \& Lupker, 1996; Hino, Lupker, \& Pexman, 2002; Pecher, 2001; Pexman \& Lupker, 1999; Pexman, Lupker, \& Jared, 2001). The NOF manipulation seemed to be a strong test of this claim. All of the words had only one meaning, and all were concrete terms; assuming that McRae et al. (1997) were correct about featural representations, words with many features should generate relatively more semantic activation than would words with fewer features. The fact that NOF effects were observed in Pexman et al.'s (2002) study provided support for the semantic feedback activation idea. The observed NOF effects also provided support, albeit indirect, for the notion of distributed representation for word meaning. The debate over local versus distributed representation is ongoing (see, e.g., Page, 2000, and responses from, e.g., Ohlsson, 2000, and Plaut \& McClelland, 2000). Further evidence would be provided if NOF effects were observed in semantic tasks. The purpose of the present research was to investigate this possibility.

Modeling the number-of-features effect. Although Pexman et al.'s (2002) study is, to our knowledge, the only behavioral study demonstrating the NOF effect, we should note that this type of effect was simulated by Plaut and Shallice (1993). Plaut and Shallice's model was an attractor network and was described by Hinton and Shallice (1991). Plaut and Shallice damaged the model in order to simulate deep dyslexia and, in so doing, assessed the ability of their model to generate concreteness effects. The model involved feedforward connections between three sets of units: grapheme units, intermediate units, and sememe units. In addition, cleanup units were connected bidirectionally to the sememe units. In their simulations of concreteness effects, Plaut and Shallice actually simulated NOF effects. The semantic features in Plaut and Shallice's model were not empirically derived, but they assumed a system of featural representation. They also assumed that concrete words would activate many semantic features, whereas abstract words would activate few semantic features (see also Jones, 1985). Furthermore, they postulated that this difference in semantic richness (and degree of semantic activation) would lead to the differences typically observed for concrete and abstract words in semantic tasks. As was expected, Plaut and Shallice reported that the model read concrete words (high-NOF words) correctly more often than abstract words (low-NOF words).

On the issue of how NOF facilitated processing in the model, Plaut and Shallice (1993) stated that "it appears that the greater number of active semantic features gives 
the clean-up circuit more raw material on which to work, allowing stronger attractors to be built" (p. 469). The semantic representations for high-NOF words appeared to be more quickly organized, moving to the end state more rapidly than semantic representations for low-NOF words. Thus, the fact that high-NOF words produce more semantic activation than do low-NOF words facilitated settling of semantic representations for high-NOF words in the model.

Cree, McRae, and McNorgan (1999) also examined the effect of number of individual features (NOF) on processing in an implemented model. The model implemented by Cree et al. was an attractor network with three sets of units: word form (input) units, semantic feature (output) units, and semantic structure units, much like the cleanup units in Plaut and Shallice's (1993) model. Utilizing a backpropagation-through-time learning algorithm, the model was trained on the 190 concepts in McRae et al.'s (1997) norms. After training, words with high NOF were found to produce higher levels of initial activation because they produced more on-units in the target representation. Thus, NOF and amount of activation were positively correlated. Over time, intercorrelational density (represented by the semantic structure units) facilitated settling in the model.

\section{The Present Research}

Our central assumption was that high-NOF words should generate more semantic activation than would lowNOF words. Our predictions were that (1) there should be a processing benefit for high-NOF words in semantic tasks and (2) the processing benefit for high-NOF words in semantic tasks would be modulated by context information. That is, to the extent that context information is present, for instance, in the form of sentence context, that information can influence activation of features in the target word, so that activated features tend to be context relevant (e.g., Kellas, Paul, Martin, \& Simpson, 1991). Kellas et al. argued that highly constraining sentence contexts narrow the scope of facilitation for target words. The context restricts the features activated for the target words. Consequently, these types of sentence contexts can reduce the processing advantage enjoyed by high-NOF words. This type of context effect has been observed for concrete and abstract words. Schwanenflugel and Stowe (1989; see also Holcomb, Kounios, Anderson, \& West, 1999) demonstrated that the typical processing difference between concrete and abstract target words (observed, e.g., in naming or meaningfulness judgment tasks) was eliminated when supportive context was provided in the form of a preceding sentence fragment congruent with the meaning of the target word. We thought that this type of context manipulation might also influence NOF effects. Consequently, we hypothesized that in Experiment 1, a self-paced reading task, differences in response time (RT) for low- and high-NOF target words would be observed only when prior context was not congruent with the meaning of the target words.

In Experiment $2 \mathrm{~A}$ and Experiments $3 \mathrm{~A}, 3 \mathrm{~B}$, and $3 \mathrm{C}$, we examined whether NOF facilitated responses in semantic categorization tasks. In these semantic categorization tasks, the only context was the categories about which the participants were asked to make decisions. This type of context is certainly not constraining in the same way that sentence context is constraining. Yet the nature of the semantic categorization task may influence the meaning activation process. In relatively specific semantic categories (e.g., bird ), there are certain features that are relevant to the decision (e.g., has wings, has a beak, has feathers, etc.), and it seems possible that participants could adopt a response strategy in which they focus on the activation level of a few task-relevant features. This type of task- dependent strategy could diminish the advantage high-NOF words should have if no such strategy is being invoked. That is, in broader semantic categories (e.g., concrete noun), it is almost impossible to identify task-relevant features, so participants' focus should be broader, including a larger proportion of activated features. Consequently, the advantage for highNOF words should be larger. We manipulated this aspect of task context by asking the participants in Experiment $3 \mathrm{~A}$ to make decisions about the categories bird versus nonbird, in Experiment 3B to make decisions about the categories living versus nonliving, and in Experiment 3C to make decisions about the categories abstract versus concrete. We predicted that NOF effects would be smaller in Experiment 3A, larger in Experiment 3B, and larger still in Experiment 3C.

\section{EXPERIMENT 1}

\section{Method}

Participants. In each of the following experiments, the participants were undergraduate students at the University of Calgary, who participated for bonus credit in a psychology course. All the participants had normal or corrected-to-normal vision and reported that English was their first language. There were 37 participants in Experiment 1 . We created three versions of this experiment so that each target word would appear in each context condition (highly congruent context, moderately congruent context, and incongruent context). The participants were assigned to versions by their order of appearance at the laboratory, so that Participant 1 was assigned to Version 1, Participant 2 to Version 2, and so on.

Stimuli. The target words were 24 low-NOF words and 24 highNOF words, selected from the norms provided by Ken McRae (e.g., McRae et al., 1997). These were virtually the same sets of 25 lowNOF and 25 high-NOF words as those used in Pexman et al.'s (2002) experiments, except that here we removed one of the low-NOF words (leotards) and one of the high-NOF words (trousers) because we expected that these particular words would be difficult to prime in sentences. All of the target words were concrete nouns, and the two word sets were matched, as much as possible, for word length and word frequency (Kučera \& Francis, 1967) and also, on the basis of ratings obtained by Pexman et al. (2002) in pilot testing, for number of meanings. Mean values for the word sets on each of these dimensions are presented in Table 1. The target words are presented in the Appendix.

The target word stimuli were placed in three context conditions: highly congruent, moderately congruent, and incongruent. In order to construct the sentences used in this experiment, we devised a large number of potential sentence contexts (four for each target word). These potential sentence fragments were all 8-10 words long. The sentences were also very similar in structure, in that they each began 
Table 1

Mean Characteristics of Stimuli Presented in Experiments 1and 3

\begin{tabular}{lcccccr}
\hline & $\begin{array}{c}\text { Number } \\
\text { of Words }\end{array}$ & NOF & $\begin{array}{c}\text { K \& F } \\
\text { Frequency }\end{array}$ & $\begin{array}{c}\text { Word } \\
\text { Length }\end{array}$ & NOM & $\begin{array}{r}\text { Feature } \\
\text { Density }\end{array}$ \\
\hline Experiment 1 & & & & & & \\
$\quad$ Low NOF & 24 & 12.00 & 11.21 & 6.21 & 1.09 & \\
$\quad$ High NOF & 24 & 20.46 & 14.63 & 5.42 & 1.07 & \\
Experiment 1 (density controlled) & & & & \\
$\quad$ Low NOF & 15 & 11.93 & 13.00 & 5.73 & 1.09 & 478.07 \\
$\quad$ High NOF & 15 & 19.93 & 14.67 & 5.13 & 1.09 & 504.07 \\
Experiment 3 & & & & & & \\
$\quad$ Low NOF & 12 & 11.58 & 2.50 & 6.58 & 1.06 & 867.60 \\
High NOF & 12 & 17.25 & 2.50 & 6.16 & 1.11 & $1,225.13$ \\
\hline
\end{tabular}

Note-Density values for Experiment 3 were based on the 13 stimuli that were included in McRae, de Sa, and Seidenberg's (1997) norms. Density values were not available for the newer, larger set of norms, from which the complete set of 24 bird names were chosen. NOF, number of features; NOM, number of meanings; K \& F frequency, Kučera \& Francis (1967) frequency count per million.

with a 3- or 4-word topicalized phrase and ended with the matrix clause. In a pilot study, we presented these sentence fragments in a cloze task to ensure that the contexts were equally congruent for the high- and the low-NOF words. Forty participants, who did not take part in the actual experiment, were presented with one of two sets of 48 sentence fragments. These participants were asked to write down the word they felt best completed the sentence. Sentence fragments were then chosen, on the basis of the cloze data, to create the three contexts. A sentence fragment was selected as highly congruent if a minimum of $66 \%$ of the participants had completed the sentence with the actual target word. On average, for low-NOF target words, $79.2 \%$ of the pilot study participants completed the sentence with the target word. For high-NOF target words, $79.6 \%$ of the participants completed the sentence with the target word. A sentence fragment was selected as moderately congruent if a maximum of $33 \%$ of the participants had completed the sentence with the actual target word. On average, for low-NOF target words, $8.2 \%$ of the participants completed the sentence with the actual target word, and for high-NOF target words, $4.8 \%$ of the participants completed the sentence with the target word. Incongruent sentences were created by mixing sentence fragments and target words so that each sentence ended with an unrelated target word.

In addition, we constructed wrap-up sentences to follow each sentence fragment and target word. These were all eight words in length, were of similar structure, and were consistent with the meaning of the sentence they followed. We included wrap-up sentences so that the target word would not be the last word presented in a given trial. In the moving windows paradigm, RTs tend to be inflated for the last word presented on a given screen, likely because participants are preparing for the comprehension question that follows. Example sentences are presented in Table 2.

Procedure. Pairs of sentences (sentence fragment + target word + wrap-up sentence) were presented to the participants on a 17-in. Sony Trinitron monitor controlled by a Macintosh G3 computer, using PsyScope (Cohen, MacWhinney, Flatt, \& Provost, 1993) in a one- word-at-a-time moving window format. Thus, pairs of sentences were initially presented on the screen with each nonspace character replaced by a dash. The participants pressed the middle button on a PsyScope response box to reveal the first word in the first sentence. Each subsequent buttonpress revealed the next word and replaced the previous word with dashes. The participants read each pair of sentences in this manner and then answered a yes or no comprehension question. Comprehension questions addressed content in the sentence fragments and the wrap-up sentences and did not address the target word. Example comprehension questions are presented in Table 2 . Testing sessions began with 10 practice sentence pairs. The participants then completed the 48 experimental trials. The participants were instructed to read at a pace that resembled how they would typically read a magazine or a newspaper. One-word-at-a-time reading latencies were recorded with millisecond accuracy via the button box, measured as the time interval between successive buttonpresses.

\section{Results and Discussion}

For the self-paced reading task, a trial was excluded from the RT analysis if an incorrect response was made to the comprehension question for that trial $(5.01 \%)$ or if the RT for the target word was faster than $150 \mathrm{msec}$ or slower than 2,500 msec (fewer than $1 \%$ of the trials). Mean RTs for the target word, as well as mean comprehension question errors, as a function of context condition and NOF condition, are presented in Table 3. In all of these experiments, the data were analyzed with subjects and, separately, items treated as random factors. For this experiment, RTs for target words were analyzed, first with 3 (context conditions: highly congruent, moderately congruent, or incongruent) $\times 2$ (NOF: high or low) analyses of variance (ANOVAs), with context as a within-subjects and within-

Table 2

Examples of Sentences and Comprehension Questions Presented in Experiment 1, as a Function of Context Condition

\begin{tabular}{|c|c|c|c|c|}
\hline Context Condition & Sentence Fragment & Target Word & Wrap-Up Sentence & Comprehension Question \\
\hline Highly congruent & $\begin{array}{l}\text { After the crash, Bob was } \\
\text { nervous about getting on an }\end{array}$ & airplane & $\begin{array}{l}\text { It took time to get over } \\
\text { his fear. }\end{array}$ & $\begin{array}{l}\text { Was Bob afraid following } \\
\text { the crash? (yes) }\end{array}$ \\
\hline Moderately congruent & $\begin{array}{l}\text { When I go home, I tend } \\
\text { to travel by }\end{array}$ & airplane & $\begin{array}{l}\text { It is more expensive } \\
\text { than taking the bus. }\end{array}$ & $\begin{array}{l}\text { Do I tend to travel by bus } \\
\text { when I go home? (no) }\end{array}$ \\
\hline Incongruent & $\begin{array}{l}\text { After a heavy snowfall, } \\
\text { Joel has to wear his }\end{array}$ & airplane & $\begin{array}{l}\text { It is too cold to wear } \\
\text { running shoes. }\end{array}$ & $\begin{array}{l}\text { Does Joel wear running } \\
\text { shoes in the snow? (no) }\end{array}$ \\
\hline
\end{tabular}


Table 3

Mean Target Word (RTs, With Standard Deviations),

NOF Effects, and Comprehension Errors, as a Function of Context Condition in Experiment 1 (Self-Paced Reading Task)

\begin{tabular}{|c|c|c|c|c|c|c|}
\hline \multirow[b]{2}{*}{ Word Type } & \multirow[b]{2}{*}{ Context Condition } & \multicolumn{2}{|c|}{ Target Word RT } & \multirow[b]{2}{*}{ NOF Effect } & \multicolumn{2}{|c|}{$\begin{array}{c}\text { Comprehension } \\
\text { Errors }\end{array}$} \\
\hline & & $M$ & $S D$ & & $M$ & $S D$ \\
\hline \multirow[t]{3}{*}{ Low NOF } & highly congruent & 468 & 267 & +17 & 3.72 & 18.91 \\
\hline & moderately congruent & 488 & 341 & +17 & 4.05 & 19.82 \\
\hline & incongruent & 614 & 462 & $+96^{*}$ & 9.12 & 28.83 \\
\hline \multirow[t]{3}{*}{ High NOF } & highly congruent & 451 & 251 & & 2.70 & 16.24 \\
\hline & moderately congruent & 471 & 305 & & 3.04 & 17.20 \\
\hline & incongruent & 518 & 353 & & 7.43 & 26.31 \\
\hline
\end{tabular}

Note-NOF, number of features. $* p<.05$.

items factor and NOF as a within-subjects and betweenitems factor and, second, with planned comparisons examining NOF effects in each context condition. The same analyses were also applied to comprehension question errors.

Target word RTs. The interaction of context and NOF was significant in the subjects analysis $\left[F_{\mathrm{s}}(2,72)=3.20\right.$, $M S_{\mathrm{e}}=11,965.66, p<.05 ; F_{\mathrm{i}}(2,92)=2.05, M S_{\mathrm{e}}=$ $9,437.59, p=.13]$. There was also a significant main effect of context $\left[F_{\mathrm{s}}(2,72)=15.65, M S_{\mathrm{e}}=13,552.42, p<\right.$ $\left..001 ; F_{\mathrm{i}}(2,92)=15.96, M S_{\mathrm{e}}=9,437.59, p<.001\right]$, so that RTs were slowest for target words presented in the incongruent context condition. There was also a significant main effect of NOF in the subjects analysis $\left[F_{\mathrm{s}}(1,36)=\right.$ $5.44, M S_{\mathrm{e}}=18,857.51, p<.05 ; F_{\mathrm{i}}(1,46)=3.90, M S_{\mathrm{e}}=$ $9,456.99, p=.05]$; responses were generally slower for low-NOF words. Planned comparisons revealed the source of the interaction: The NOF effect was significant in the incongruent context condition $\left[t_{\mathrm{s}}(36)=2.59, S E=\right.$ $\left.36.95, p<.05 ; t_{\mathrm{i}}(46)=2.36, S E=33.13, p<.05\right]$, but not in the highly congruent $\left(t_{\mathrm{s}}<1 ; t_{\mathrm{i}}<1\right)$ or moderately congruent $\left[t_{\mathrm{s}}(36)=1.69, S E=27.42, p=.10 ; t_{\mathrm{i}}<1\right]$ context conditions. Thus, NOF had a significant impact on reading latencies for target words when the target words followed the incongruent context, but not when the target words followed the highly congruent or the moderately congruent contexts.

Comprehension question errors. The only significant effect was a main effect of context $\left[F_{\mathrm{s}}(2,72)=11.25, M S_{\mathrm{e}}=\right.$ $\left.53.65, p<.001 ; F_{\mathrm{i}}(2,92)=4.50, M S_{\mathrm{e}}=84.12, p<.05\right]$, so that more errors were made for comprehension questions that followed sentences presented in the incongruent context condition.

These results demonstrated that NOF for the target word influenced reading time for the target word and that, as was hypothesized, the effect was limited to the incongruent context condition. Thus, in this type of semantic (reading) task, there is an advantage for words with many features (over words with few features) only when the context has biased the reader to expect an entirely different concept to be mentioned.

It is generally assumed that reading time for a word presented in sentence context captures a combination of processes: context-driven expectation, activation of word meaning, and integration, although there are arguments about the manner in which, and extent to which, these processes interact (see, e.g., some of the recent literature on lexical ambiguity resolution: Dopkins, Morris, \& Rayner, 1992; Kellas \& Vu, 1999; Martin, Vu, Kellas, \& Metcalf, 1999; Rayner, Binder, \& Duffy, 1999; Vu \& Kellas, 1999). We offer an interactionist account here. The NOF manipulation should affect only the word meaning activation process. In contrast, the context manipulation will affect expectation, so that in the highly congruent context condition and, to some degree, in the moderately congruent context conditions, there is a strong expectation for the target word, but in the incongruent context condition, there is no expectation for the target word (in fact, an entirely different word is expected). In the congruent context conditions, this expectation process will interact with the meaning activation process. That is, context-relevant features in the target word will be preactivated. In other words, features of the target word will be activated before the target word is perceived. Some of these preactivated features may be those listed in the feature-listing task (and included in McRae et al.'s, 1997, norms), but some will be context-dependentfeatures not listed in the feature-listing task. Since the meaning activation process will be constrained by context in this way, this will eliminate the advantage high-NOF words typically have in the meaning activation process. Thus, reading times are equivalent for highand low-NOF words presented in the congruent contexts.

Given this account, one might wonder why the NOF effect did not begin to emerge in the moderately congruent context condition. Our speculation is that, although the sentence fragments in the moderately congruent condition did not tend to lead to an expectation for the actual target word, they did tend to lead to an expectation for similar words. For instance, in the example of a moderately congruent context sentence fragment presented in Table 2, the sentence clearly needs to be completed by a mode of transportation. The meaning of airplane (the actual target word) shares many features with other modes of transportation (e.g., has wheels, used for travel, carries passengers). Thus, even the moderately congruent context sentence fragments could have preactivated particular features, resulting in a nonsignificant NOF effect for target words.

In Experiment 1, there was a semantic processing advantage gained from NOF only when context did not con- 
strain activation of features of the target concept. We next tested whether NOF effects would emerge in a semantic categorization task and also attempted to disentangle NOF from other semantic factors. In particular, in Experiment 1, we did not control feature density. Intercorrelational density was derived by McRae et al. (1997) and was also described in Cree et al. (1999) as an index of semantic structure. McRae et al. calculated intercorrelational feature density for the 190 concepts in their norms. First, correlations were calculated for each pair of features that appeared in at least three concepts. Then the percentage of shared variance between each pair of a concept's features (for correlations that were significant at the $p<.01$ level) were summed. Feature density is essentially a measure of how tight a concept is in semantic space. In McRae et al.'s norms, NOF and feature density are positively correlated $[r(190)=.38, p<.01]$. These two variables are also positively correlated in the subset of words chosen from those norms for the present Experiment $1[r(48)=.54, p<$ $.01]$. Consequently, it seemed possible that feature density might have influenced response latencies in Experiment 1. That is, we may have observed effects of density, and not NOF effects per se, in the present Experiment 1. We first dealt with this issue in a post hoc way, by conducting additional analyses on the data from Experiment 1 . In these analyses, we selected a subset of words such that mean density was equivalent for low-NOF and high-NOF words. Mean characteristics for these subsets are presented in Table 1.

For the data from Experiment 1, when we used responses for word sets in which density was equated, there was a $70-\mathrm{msec}$ NOF effect that was significant by subjects in the incongruent context condition $\left[t_{\mathrm{s}}(36)=2.39, S E=39.66\right.$, $p<.05 ; t_{\mathrm{i}}(28)=1.79, S E=40.06, p=.09$ ]. Thus, when feature density was equated across NOF conditions, the effects for NOF were essentially unchanged. It is certainly possible, however, that density has unique effects on responses in this type of task but our stimuli in the previous experiment were not selected to test this. Ideally, to investigate this issue, one would conduct regression analyses, using RT and errors in the reading task as criterion variables, with NOF, density, and other item characteristics as predictor variables. Unfortunately, the previous experiment involved a small number of items, and since the regression analyses would essentially be item analyses, we would have very little power to detect significant relationships between the criterion variables and the various predictors.

To remedy this problem and investigate the issue of feature density effects in a more a priori way, we next conducted two experiments involving the entire set of concepts (190) in McRae et al.'s (1997) norms. With this larger set of concepts, we were able to conduct regression analyses with sufficient power to detect (potentially) independent effects of NOF and density. Experiment $2 \mathrm{~A}$ was a semantic categorization task (concrete vs. abstract), and Experiment 2B was an LDT (word vs. nonword). In Experiments $2 \mathrm{~A}$ and $2 \mathrm{~B}$, we also examined whether NOF would have a similar effect on living thing concepts and artifact concepts, in order to determine whether type of concept would moderate NOF effects. Finally, in Experiment 3, we examined whether NOF would facilitate processing for items within a single category, in order to control for some of the cross-category variability that may have been present in our prior experiments.

\section{EXPERIMENT 2}

\section{Method}

Participants. There were 38 participants in Experiment 2A and 38 participants in Experiment 2B.

Stimuli. The critical stimuli for this experiment were 190 words from McRae et al.'s (1997) norms. All of these words were concrete nouns. The filler stimuli for Experiment 2A were 190 words considered, by the experimenters, to be abstract (e.g., metaphor, observe, etc.). The foil stimuli for Experiment 2B were 190 pseudowords taken from Pexman and Lupker (1999) and Pexman et al. (2001).

Procedure. On each trial, a word was presented in the center of a 17-in. Sony Trinitron monitor controlled by a Macintosh G3 computer, using PsyScope (Cohen et al., 1993). In Experiment 2A, the participants were asked to decide whether each word was concrete or abstract and to indicate their response by pressing either the left button (for abstract) or the right button (for concrete) on a PsyScope response box. Testing sessions began with 10 practice trials, during which the participants were given verbal feedback for incorrect responses. The intertrial interval was $2,000 \mathrm{msec}$, and the words were presented in a different random order for each participant.

The procedure for Experiment $2 \mathrm{~B}$ was the same as that in Experiment $2 \mathrm{~A}$, except that the participants were asked to decide whether each letter string was a word or nonword and to indicate their response by pressing either the left button (for nonword) or the right button (for word) on a PsyScope response box.

\section{Results and Discussion}

In this experiment, a trial was considered an error and was excluded from the RT analysis if the RT was longer than $1,500 \mathrm{msec}$ or shorter than $250 \mathrm{msec}$ (fewer than $1 \%$ of trials) or if the participants made an incorrect response (5.91\% of the trials in Experiment 2A, 6.23\% of the trials in Experiment 2B). Mean RTs and error percentages are presented in Table 4. For responses to abstract words in Experiment $2 \mathrm{~A}$, the mean RT was $706 \mathrm{msec}$, and the mean error percentage was $6.42 \%$. For nonword responses in Experiment 2B, the mean RT was $613 \mathrm{msec}$, and the mean error percentage was $6.43 \%$.

Standard multiple regression analyses were conducted using RT and, separately, percentage of errors for the 190 concrete words in Experiment 2A as criterion variables. Predictor variables were NOF, feature density, Kučera and Francis (1967) word frequency, and word length. Values for NOF and feature density were taken from McRae et al.'s (1997) norms. Correlations between all of these variables are presented in Table 4. Summaries of the regression analyses are presented in Table 5. With RT as the criterion variable, the regression equation was significant $\left[R^{2}=\right.$ $.18 ; F(4,185)=9.82, p<.001]$. Importantly, the predictor variables that had significant, unique relationships with RT were NOF and word length. Feature density and word frequency were not significant predictors. With er- 
Table 4

Means, Standard Deviations, and Intercorrelations for Response Times

(RTs) and Percentages of Errors for Experiments 2A

(Semantic Categorization Task) and 2B (Lexical Decision Task) and Word Characteristic Predictor Variables

\begin{tabular}{lcccccc}
\hline \multicolumn{1}{c}{ Measure } & $M$ & $S D$ & 1 & 2 & 3 & 4 \\
\hline Experiment 2A & & & & & & \\
$\quad$ RT & 607 & 77 & $-.31 \dagger$ & -.05 & -.08 & $.28 \dagger$ \\
$\quad$ Errors & 5.40 & 9.83 & $-.28 \dagger$ & -.06 & $.17^{*}$ & -.02 \\
$\quad$ Experiment 2B & & & & & & \\
$\quad$ RT & 557 & 71 & $-.25 \dagger$ & .03 & $-.23^{*}$ & $.27 \dagger$ \\
$\quad$ Errors & 6.03 & 9.84 & $-.23 \dagger$ & -.01 & $-.15^{*}$ & -.10 \\
Predictor variable & & & & & & \\
$\quad$ 1. NOF & 15.59 & 3.24 & - & & & \\
2. Feature density & 558.54 & 472.46 & $.38 \dagger$ & - & & \\
3. K \& F frequency & 18.28 & 34.05 & -.05 & -.07 & - & \\
$\quad$ 4. Word length & 5.63 & 1.81 & -.02 & .12 & $-.32 \dagger$ & - \\
\hline
\end{tabular}

Note-NOF, number of features; K \& F frequency, Kučera \& Francis (1967) frequency count per million. $* p<.05 . \quad{ }^{\dagger} p<.01 . \quad d f=190$.

rors as the criterion variable, the regression equation was significant $\left[R^{2}=.09 ; F(4,185)=5.52, p<.001\right]$. The predictor variables that had significant, unique relationships with errors in this analysis were NOF and word frequency. Again, feature density was not a significant predictor.

With the same predictor variables, standard multiple regression analyses were conducted using RT and, separately, percentage of errors for the 190 concrete words in Experiment 2B as criterion variables. With RT as the criterion variable, the regression equation was significant $\left[R^{2}=.17 ; F(4,185)=9.31, p<.001\right]$. Importantly, the predictor variables that had significant, unique relationships with RT were NOF, word frequency, and word length. Feature density was not a significant predictor. With errors as the criterion variable, the regression equation was significant $\left[R^{2}=.11 ; F(4,185)=5.89, p<.001\right]$. The predictor variables that had significant, unique relationships with errors in this analysis were NOF, word frequency, and word length. Again, feature density was not a significant predictor.

Thus, feature density was not a significant predictor of RT or errors in the semantic categorization task or in the LDT, whereas NOF was a significant predictor. We next turned to the issue of whether NOF or feature density effects would be observed when the data for different types of concepts were considered separately. McRae et al. (1997) reported that although living things (fruit, vegetables, mammals, and birds) and artifacts (clothing, furniture, kitchen items, tools, vehicles, and weapons) tended to have the same mean number of features, living things had more densely intercorrelated features. We next repeated the regression analyses, this time examining responses for living things separately from responses for artifacts. Mean RTs and error percentages for Experiment $2 \mathrm{~A}$ and Experiment $2 \mathrm{~B}$, as a function of concept type (living thing vs. artifact) are presented in Table 6 .

Living things. Standard multiple regression analyses were conducted using Experiments 2A and 2B RT and, separately, percentage of errors for the 76 living thing con- cepts as criterion variables. Predictor variables were NOF, feature density, Kučera and Francis (1967) word frequency, and word length. Correlations between all of these variables are presented in Table 6. Summaries of the regression analyses are presented in Table 7. With Experiment $2 \mathrm{~A}$ (semantic categorization task) RT as the criterion variable, the regression equation was significant $\left[R^{2}=\right.$ $.20 ; F(4,71)=4.45, p<.005]$. Importantly, the only predictor variable that had a significant, unique relationship with RT was NOF. With Experiment 2A errors as the criterion variable, the regression equation was not significant $\left[R^{2}=.08 ; F(4,71)=1.43, p=.23\right]$. None of the pre-

Table 5

Results of Regression Analyses in Experiments 2A (Semantic Categorization Task) and $2 B$ (Lexical Decision Task)

\begin{tabular}{lrrrr}
\hline \multicolumn{1}{c}{ Variable } & $B$ & $S E B$ & $\beta$ & $s r$ \\
\hline \multicolumn{5}{c}{ Experiment 2A (Concrete vs. Abstract) } \\
RT & \multicolumn{4}{c}{} \\
NOF & -7.60 & 1.72 & $-.32 \ddagger$ & -.30 \\
Feature density & 0.01 & 0.01 & .04 & .04 \\
K \& F frequency & -0.00 & 0.16 & -.00 & -.00 \\
Word length & 11.64 & 3.02 & $.27 \ddagger$ & .26 \\
Errors & & & & \\
NOF & -0.89 & 0.23 & $-.29 \ddagger$ & -.27 \\
Feature density & 0.00 & 0.00 & .06 & .05 \\
K \& F frequency & 0.05 & 0.02 & $.17 *$ & .16 \\
Word length & 0.11 & 0.40 & .02 & .02
\end{tabular}

Experiment 2B (Word vs. Nonword)

RT

\begin{tabular}{lrrrr} 
NOF & -6.28 & 1.59 & $-.29 \ddagger$ & -.27 \\
Feature density & 0.01 & 0.01 & .10 & .09 \\
K \& F frequency & -0.36 & 0.15 & $-.17 *$ & -.16 \\
Word length & 7.88 & 2.79 & $.20 \dagger$ & .19 \\
Errors & & & & \\
NOF & -0.84 & 0.23 & $-.28 \ddagger$ & -.26 \\
Feature density & 0.00 & 0.00 & .10 & .10 \\
K \& F frequency & -0.06 & 0.02 & $-.22 \dagger$ & -.21 \\
Word length & -0.99 & 0.40 & $-.18^{*}$ & -.17 \\
\hline
\end{tabular}

Note-NOF, number of features; K \& F frequency, Kučera \& Francis $(1967)$ frequency count per million; RT, response time. $* p<.05$. ${ }^{\dagger} p<.01 . \stackrel{\ddagger}{\ddagger} p<.001$. 
Table 6

Means, Standard Deviations, and Intercorrelations for Response Times (RTs) and Percentages of Errors for Experiments 2A (Semantic Categorization Task) and 2B (Lexical Decision Task) and Word Characteristic Predictor Variables, as a Function of Concept Type (Living Thing vs. Artifact)

\begin{tabular}{|c|c|c|c|c|c|c|}
\hline Measure & $M$ & $S D$ & 1 & 2 & 3 & 4 \\
\hline \multicolumn{7}{|c|}{ Living Thing Concepts $(n=76)$} \\
\hline \multicolumn{7}{|l|}{ Experiment $2 \mathrm{~A}$} \\
\hline RT & 597 & 87 & $-.30 \dagger$ & .21 & $-.25^{*}$ & $.25 *$ \\
\hline Errors & 4.74 & 9.77 & -.19 & .10 & -.17 & .02 \\
\hline \multicolumn{7}{|l|}{ Experiment $2 \mathrm{~B}$} \\
\hline RT & 555 & 69 & $-.28 *$ & $.24 *$ & $-.33 \dagger$ & $.28 *$ \\
\hline Errors & 6.17 & 10.87 & $-.23 *$ & .09 & -.19 & -.16 \\
\hline \multicolumn{7}{|l|}{ Predictor variable } \\
\hline 1. NOF & 16.53 & 3.52 & - & & & \\
\hline 2. Feature density & 845.93 & 459.90 & $.23^{*}$ & - & & \\
\hline 3. $\mathrm{K} \& \mathrm{~F}$ frequency & 9.07 & 16.87 & .18 & -.15 & - & \\
\hline 4. Word length & 5.79 & 1.87 & -.09 & $.30 \dagger$ & $-.29 *$ & - \\
\hline \multicolumn{7}{|c|}{ Artifact Concepts $(n=114)$} \\
\hline \multicolumn{7}{|l|}{ Experiment $2 \mathrm{~A}$} \\
\hline RT & 614 & 69 & $-.29 \dagger$ & $-.19 *$ & -.07 & $.33+$ \\
\hline Errors & 5.84 & 9.88 & $-.35 \ddagger$ & -.15 & $.26 \dagger$ & -.04 \\
\hline \multicolumn{7}{|l|}{ Experiment $2 \mathrm{~B}$} \\
\hline RT & 558 & 73 & $-.23^{*}$ & -.11 & $-.24 *$ & $.28 \dagger$ \\
\hline Errors & 5.93 & 9.13 & $-.24 *$ & -.12 & -.17 & -.04 \\
\hline \multicolumn{7}{|l|}{ Predictor variable } \\
\hline 1. NOF & 14.96 & 2.90 & - & & & \\
\hline 2. Feature density & 366.95 & 374.66 & $.39 \$$ & - & & \\
\hline 3. $\mathrm{K} \& \mathrm{~F}$ frequency & 24.42 & 40.68 & -.05 & .13 & - & \\
\hline 4. Word length & 5.53 & 1.77 & .01 & -.07 & $-.34 \$$ & - \\
\hline
\end{tabular}

Note-NOF, number of features; K \& F frequency, Kučera \& Francis (1967) frequency count

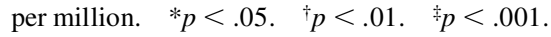

dictor variables had significant, unique relationships with errors.

With Experiment 2B (LDT) RT as the criterion variable, the regression equation was significant $\left[R^{2}=.24 ; F(4,71)=\right.$ $5.55, p<.001]$. Importantly, the predictor variables that had significant, unique relationships with RT were NOF and feature density. The direction of the relationship with density was surprising: As NOF increased, RT decreased, but increases in density were related to increases in RT. With Experiment 2B errors as the criterion variable, the regression equation was significant $\left[R^{2}=.17 ; F(4,71)=\right.$ $3.61, p<.05]$. The predictor variables that had significant, unique relationships with errors were NOF and word length.

Artifacts. Standard multiple regression analyses were conducted using Experiments 2A and 2B RT and, separately, percentage of errors for the 114 artifact concepts as criterion variables. Predictor variables were NOF, feature density, Kučera and Francis (1967) word frequency, and word length. Correlations between all of these variables are presented in Table 6. Summaries of the regression analyses are presented in Table 7. With Experiment 2A (semantic categorization task) RT as the criterion variable, the regression equation was significant $\left[R^{2}=.21\right.$; $F(4,109)=7.07, p<.001]$. Importantly, the predictor variables that had significant, unique relationships with
RT were NOF and word length. Feature density was not a significant predictor. With Experiment $2 \mathrm{~A}$ errors as the criterion variable, the regression equation was significant $\left[R^{2}=.19 ; F(4,109)=6.33, p<.001\right]$. The predictor variables that had significant, unique relationships with errors were NOF and word frequency. Again, feature density was not a significant predictor.

With Experiment 2B (LDT) RT as the criterion variable, the regression equation was significant $\left[R^{2}=.16\right.$; $F(4,109)=5.02, p<.001]$. Importantly, the predictor variables that had significant, unique relationships with RT were NOF and length. With Experiment 2B errors as the criterion variable, the regression equation was significant $\left[R^{2}=.10 ; F(4,109)=3.04, p<.05\right]$. The predictor variables that had significant, unique relationships with errors were NOF and word frequency.

Thus, when we considered responses for living thing concepts separately from responses for artifact concepts, feature density emerged as a significant predictor of LDT responses to living thing concepts (but not to artifacts), and the relationship was positive, so that concepts with denser featural representations tended to produce slower RTs in the LDT. In contrast, NOF remained a significant predictor of responses in both tasks and for both types of concepts.

We would argue that the relationship between feature density and LDT responses for living things is consistent 
with the notion of semantic feedback activation (e.g., Hino \& Lupker, 1996; Hino et al., 2002). Living thing concepts tend to have higher density than artifact concepts. Thus, the semantic representations for living thing concepts are relatively dense to begin with (although, as Cree et al., 1999, noted, semantic representations are generally quite sparse). The data suggest that when a concept has particularly high density, this is related to slower LDT RTs. According to the semantic feedback activation idea, LDT performance is influenced by semantic activation only in terms of semantic feedback activation to the orthographic units. For densely represented concepts, features could be so highly correlated that they provide less feedback activation to the orthographic units than do less dense representations. Essentially, relatively high density dilutes the many-to-one nature of facilitatory semantic feedback. This explanation is admittedly post hoc and will require elaboration and testing in future work.

McRae and colleagues (e.g., Cree et al., 1999) have argued that concrete/abstract decision task responses map onto settling time quite well in their model. That model also predicts that feature density should be a significant predictor of settling time. Yet we observed no effect of feature density on concrete/abstract decision RTs or errors for living thing or artifact concepts. Thus, at least in regard to the effect of intercorrelational density, our data appear to be inconsistent with that model. A key issue may be that our data involve single-word recognition, whereas their model was devised to explain priming effects. Although NOF appears to be an important factor in single-word recognition, density may be important to priming behavior.

\section{EXPERIMENT 3}

One goal of Experiment 3 was to evaluate further our initial predictions, for this article, involving an interaction of NOF and context conditions. Another goal was to separate NOF effects from cross-category variability. That is, the items used in Experiments 1 and 2 were from many different categories. Those categories differ in many ways beyond the living thing versus artifact distinction. Some categories have more perceptual features than others, some are larger than others, and some are likely more coherent than others. These factors were still uncontrolled. After we had completed Experiments 1 and 2, Ken McRae shared with us a new, larger set of norms. These were feature-listing data for 541 concepts. These new norms included many more exemplars for each superordinate category than had been included in McRae et al.'s (1997) previous norms. As such, it was possible to manipulate NOF within a superordinate category (birds); there were sufficient bird exemplars (39) in the new norms that we could select a subset of items in which typicality, number of meanings, frequency, and length were controlled but NOF varied. We used these bird items in Experiment 3 and revisited the issue of context effects. Here, we used three different versions of the semantic categorization task. In Ex-
Table 7

Results of Regression Analyses in Experiments 2A (Semantic Categorization Task) and 2B (Lexical Decision Task) as a Function of Concept Type (Living Thing vs. Artifact)

\begin{tabular}{lrrrr}
\hline \multicolumn{1}{c}{ Variable } & $B$ & $S E B$ & $\beta$ & $s r$ \\
\hline \multicolumn{5}{c}{ Experiment 2A (Living Thing Concepts) } \\
RT & & & & \\
NOF & -7.80 & 2.79 & $-.31 \dagger$ & -.30 \\
Feature density & 0.04 & 0.02 & .22 & .20 \\
K \& F frequency & -0.65 & 0.58 & -.13 & -.12 \\
Word length & 5.59 & 5.41 & .12 & .11 \\
Errors & & & & \\
NOF & -0.57 & 0.34 & -.21 & -.19 \\
Feature density & 0.00 & 0.00 & .15 & .14 \\
K \& F frequency & -0.08 & 0.07 & -.13 & -.12 \\
Word length & -0.44 & 0.65 & -.09 & -.08
\end{tabular}

Experiment 2A (Artifact Concepts)

RT

$\begin{array}{lrllr}\text { NOF } & -6.23 & 2.22 & -.26 \dagger & -.24 \\ \text { Feature density } & -0.02 & 0.02 & -.08 & -.07 \\ \text { K \& F frequency } & 0.08 & 0.16 & .05 & .05 \\ \text { Word length } & 13.59 & 3.54 & .35 \ddagger & .33 \\ \text { Errors } & & & & \\ \text { NOF } & -1.06 & 0.32 & -.31 \ddagger & -.29 \\ \text { Feature density } & -0.00 & 0.00 & -.06 & -.06 \\ \text { K \& F frequency } & 0.07 & 0.02 & .28 \dagger & .26 \\ \text { Word length } & 0.31 & 0.51 & .06 & .05\end{array}$

Experiment 2B (Living Thing Concepts)

RT

$\begin{array}{lrccr}\text { NOF } & -5.54 & 2.14 & -.28^{*} & -.27 \\ \text { Feature density } & 0.04 & 0.02 & .24 * & .22 \\ \text { K \& F frequency } & -0.85 & 0.45 & -.21 & -.20 \\ \text { Word length } & 4.30 & 4.16 & .12 & .11 \\ \text { Errors } & & & & \\ \text { NOF } & -0.85 & 0.36 & -.27 * & -.26 \\ \text { Feature density } & 0.01 & 0.00 & .21 & .19 \\ \text { K \& F frequency } & -0.13 & 0.07 & -.19 & -.18 \\ \text { Word length } & -1.80 & 0.69 & -.31^{*} & -.28\end{array}$

Experiment 2B (Artifact Concepts)

RT

\begin{tabular}{lrccr} 
NOF & -6.21 & 2.41 & $-.25^{*}$ & -.23 \\
Feature density & 0.00 & 0.02 & .02 & .02 \\
K \& F frequency & -0.31 & 0.17 & -.18 & -.16 \\
Word length & 9.01 & 3.85 & $.22^{*}$ & .21 \\
Errors & & & & \\
NOF & -0.78 & 0.31 & $-.25^{*}$ & -.23 \\
Feature density & 0.00 & 0.00 & -.00 & -.00 \\
K \& F frequency & -0.05 & 0.02 & $-.22^{*}$ & -.20 \\
Word length & -0.59 & 0.50 & -.11 & -.11 \\
\hline
\end{tabular}

Note-NOF, number of features; K \& F frequency, Kučera \& Francis (1967) frequency count per million; RT, response time. $* p<.05$. ${ }^{\dagger} p<.01$. $\stackrel{\ddagger}{\ddagger} p<.001$.

periment $3 \mathrm{~A}$, the decision categories were bird versus nonbird. In Experiment 3B, the decision categories were living versus nonliving, and in Experiment $3 \mathrm{C}$, the decision categories were concrete versus abstract. Importantly, we were able to use the same critical bird items as exemplars in each version of the task. This allowed examination of the way that the category context modulated NOF effects. Recall that our prediction was that more specific categories would reduce the magnitude of the NOF effect. 


\section{Method}

Participants. There were 41 participants in Experiment 3A (1 participant was excluded due to a $50 \%$ error percentage), 40 participants in Experiment 3B, and 42 participants in Experiment 3C.

Stimuli. The critical stimuli for all three experiments were 12 lowNOF and 12 high-NOF bird names. Mean characteristics for these words are presented in Table 1. In order to ensure that the low- and the high-NOF word sets were equally representative of the bird category, we asked 30 participants, who did not take part in the actual experiment, to rate each of these words on a 7-point scale, where $1=$ not typical at all and $7=$ very typical. Mean bird typicality ratings were 4.76 for the low-NOF and 4.75 for the high-NOF words $(t<1)$. Thus, the two word sets were equally typical of the bird category.

In order to ensure that the low- and the high-NOF words were all considered to be unambiguous and that the two groups of words had equivalent numbers of meanings (NOMs), we also asked 21 participants, who did not take part in the actual experiment, to rate each of the words on a 3 -point scale, where $0=$ no meanings, $1=$ one meaning, and $2=$ more than one meaning. The 24 bird names were presented for the rating task in a list, along with 52 other nouns and four nonwords. Mean NOM ratings were 1.06 for the low-NOF and 1.11 for the high-NOF words $(t<1)$.

In Experiment 3A, there were 39 bird names, including the 24 critical bird name targets, and 39 nonbird items (e.g., banana, rabbit, cabin, etc.). In Experiment 3B, there were 72 living things (e.g., bear, apple, lettuce, etc.), including the 24 bird names, and 72 nonliving things (e.g., book, guitar, car, etc.). In Experiment 3C, there were 72 concrete words (including the 24 bird names) and 72 abstract words (e.g., metaphor, observe, etc.).

Procedure. In all three experiments, the participants completed a semantic categorization task, and the procedure was the same as that in Experiment 2A. In Experiment 3A, the participants were asked to decide whether each word was a bird or a nonbird. In Experiment $3 \mathrm{~B}$, the participants were asked to decide whether each word was a living thing or a nonliving thing. In Experiment 3C, the participants were asked to decide whether each word was concrete or abstract. In all cases, the participants were asked to indicate their response by pressing either the left button (for nonexemplars) or the right button (for exemplars) on a PsyScope response box.

\section{Results and Discussion}

In all three experiments, a trial was considered an error and was excluded from the RT analysis if the RT was longer than $1,500 \mathrm{msec}$ or shorter than $250 \mathrm{msec}$ (fewer than $1 \%$ of the trials) or if the participants made an incorrect response (7.12\% of the trials in Experiment 3A, 5.33\% of the trials in Experiment 3B, and $6.02 \%$ of the trials in Experiment $3 \mathrm{C}$ ). Mean RTs and error percentages are presented in Table 8.
We conducted 3 (task condition: $3 \mathrm{~A}, 3 \mathrm{~B}$, or $3 \mathrm{C}$ ) $\times 2$ (NOF: low or high) ANOVAs, with task condition as a between-subjects and within-items factor and NOF as a within-subjects and between-items factor, in order to determine whether the effect of NOF increased as the semantic decision was made less specific. The interaction of NOF and task condition in the RT analysis was marginally significant $\left[F_{\mathrm{s}}(2,119)=2.56, M S_{\mathrm{e}}=5,172.29, p=.08\right.$; $\left.F_{\mathrm{i}}(2,44)=3.15, M S_{\mathrm{e}}=2,265.38, p=.05\right]$ but was not significant in the error analysis $\left[F_{\mathrm{s}}(2,119)=1.26, M S_{\mathrm{e}}=\right.$ $\left.0.01, p>.05 ; F_{\mathrm{i}}<1\right]$. There was a significant main effect of NOF in the RT analysis $\left[F_{\mathrm{s}}(1,119)=79.32, M S_{\mathrm{e}}=\right.$ $5,172.29, p<.001 ; F_{\mathrm{i}}(1,22)=6.09, M S_{\mathrm{e}}=31,586.12$, $p<.05]$ and in the error analysis by subjects $\left[F_{\mathrm{s}}(1,119)=\right.$ $72.79, M S_{\mathrm{e}}=0.01, p<.001 ; F_{\mathrm{i}}(1,22)=3.82, M S_{\mathrm{e}}=0.04$, $p=.06]$. There was also a significant main effect of task condition in the RT analysis $\left[F_{\mathrm{s}}(1,119)=4.55, M S_{\mathrm{e}}=\right.$ $37,074.69, p<.01 ; F_{\mathrm{i}}(2,44)=29.86, M S_{\mathrm{e}}=2,265.38$, $p<.001]$, but not in the error analysis $\left(F_{\mathrm{s}}<1 ; F_{\mathrm{i}}<1\right)$.

In Experiment 3A (bird vs. nonbird), planned comparisons between low- and high-NOF bird names showed a significant NOF effect in the RT analysis $\left[t_{\mathrm{s}}(40)=5.15\right.$, $S E=10.86, p<.001 ; t_{\mathrm{i}}(22)=1.90, S E=34.85, p<$ $.05]$ and in the error analysis by subjects $\left[t_{\mathrm{s}}(40)=5.11\right.$, $\left.S E=0.02, p<.001 ; t_{\mathrm{i}}(22)=1.73, S E=0.05, p=.05\right]$.

In Experiment 3B (living thing vs. nonliving thing), planned comparisons between low- and high-NOF bird names showed a significant NOF effect in the RT analysis $\left[t_{\mathrm{s}}(39)=4.67, S E=17.81, p<.001 ; t_{i}(22)=2.39, S E=\right.$ $45.74, p<.05]$ and in the error analysis by subjects $\left[t_{\mathrm{s}}(39)=4.00, S E=0.02, p<.001 ; t_{\mathrm{i}}(22)=1.68, S E=\right.$ $0.05, p=.05]$.

In Experiment 3C (concrete vs. abstract), planned comparisons showed a significant NOF effect in the RT analysis $\left[t_{\mathrm{s}}(40)=5.86, S E=18.19, p<.001 ; t_{\mathrm{i}}(22)=2.58\right.$, $S E=52.08, p<.05]$ and in the error analysis $\left[t_{\mathrm{s}}(40)=5.72\right.$, $\left.S E=0.02, p<.001 ; t_{\mathrm{i}}(22)=1.96, S E=0.06, p<.05\right]$.

Across Experiment 3, the size of the NOF effect roughly doubled as the task was made less specific. This provides some support for our prediction that NOF effects are modulated by context. When the decision category was very specific (bird vs. nonbird), the participants may have focused on activation of certain task-relevant bird features, and thus, the general processing advantage for high-

Table 8

Mean Response Times (RTs) and Percentages of Errors (With Standard Deviations) for Experiment 3 (Semantic Categorization Tasks)

\begin{tabular}{|c|c|c|c|c|c|c|c|c|c|c|c|c|c|c|c|c|c|c|}
\hline \multirow[b]{3}{*}{ Word Type } & \multicolumn{6}{|c|}{ Experiment 3A (Bird vs. Nonbird) } & \multicolumn{6}{|c|}{ Experiment 3B (Living vs. Nonliving) } & \multicolumn{6}{|c|}{ Experiment $3 \mathrm{C}$ (Concrete vs. Abstract) } \\
\hline & \multicolumn{2}{|c|}{ RT } & \multicolumn{2}{|c|}{ Errors } & \multicolumn{2}{|c|}{ NOF Effect } & \multicolumn{2}{|c|}{ RT } & \multicolumn{2}{|c|}{ Errors } & \multicolumn{2}{|c|}{ NOF Effect } & \multicolumn{2}{|c|}{ RT } & \multicolumn{2}{|c|}{ Errors } & \multicolumn{2}{|c|}{ NOF Effect } \\
\hline & $M$ & $S D$ & $M$ & $S D$ & RT & Errors & $M$ & $S D$ & $M$ & $S D$ & RT & Errors & $M$ & $S D$ & $M$ & $S D$ & RT & Errors \\
\hline $\mathrm{F}$ & 639 & 272 & .00 & 35.62 & $+53 \ddagger$ & +8.00 & 664 & 281 & 13.00 & 33.81 & $+90 \ddagger$ & +7.00 市 & 747 & 345 & 15.00 & 36.01 & $+104 \ddagger$ & +11.00 \\
\hline $\mathrm{Hig}$ & 586 & 216 & & 25.21 & & & 574 & 191 & 6.00 & 23. & & & 643 & 197 & 4.00 & 19 & & \\
\hline Filler words & 557 & 166 & 6.00 & 23.90 & & & 566 & 165 & 5.00 & 22.53 & & & 627 & 209 & 3.00 & 17.75 & & \\
\hline Foils & 585 & 184 & 4.00 & 20.23 & & & 608 & 168 & 3.00 & 17.97 & & & 716 & 262 & 4.00 & 20.00 & & \\
\hline
\end{tabular}

Note-Filler words were extra bird names in Experiment 3A, living concrete terms in Experiment 3B, and living and nonliving concrete terms in Experiment 3C. Foils were living and nonliving concrete terms in Experiment 3A, nonliving concrete terms in Experiment 3B, and abstract terms in Experiment 3C. NOF, number of features. $\quad \ddagger p<.001$. 
NOF words had less impact on responses than when the decision category was more broad. Nonetheless, the NOF effect was still significant for responses in the more specific decision category. In interpreting these substantial effects for bird stimuli in Experiment 3, one could argue that perhaps there is something special about the bird category that makes NOF a particularly influential variable. We would counter this argument, however, by noting that the results of the regression analyses in Experiment 2 suggest that NOF is a significant predictor of semantic processing for both living thing concepts (which include birds) and artifact concepts. One could argue that what we observed in Experiment 3 was closer to the pure NOF effect; category variability (category size, category coherence, type of features, etc.) was controlled in Experiment 3 , whereas it had not been controlled in the previous experiments.

\section{GENERAL DISCUSSION}

The purpose of the present research was to examine NOF effects in semantic tasks in order to test the notion of distributed representation of word meaning. The results showed facilitation for high-NOF words in comparison with low-NOF words, particularly when context information was minimal or nonexistent. In other words, NOF was particularly important when the meaning activation process was not constrained by context. The term context is used here quite broadly to refer to both sentence context and context invoked by the nature of the semantic categories in semantic categorization tasks.

The fact that we observed effects of the NOF the participants tended to list for specific concepts shows, quite clearly, that even for concrete unambiguous words, there is variability in the richness of semantic representations. As such, local representation of word meaning is not viable. In order to explain our results in terms of local representation, one would have to argue that concept nodes differ in some systematic way as a function of NOF. This seems highly improbable. Instead, the results support the notion of distributed representation of word meaning.

The present results are consistent with the suggestion that the units involved in that distributed representation correspond to semantic features, of the type that participants provided in the feature-listing task used by McRae et al. (1997). Note, however, that although our results are consistent with this suggestion, they are not proof that, when activating word meaning, people literally access mental lists of features. Our speculation is that word meanings are represented in a way that is related to featural information. We will next consider the extent to which the results could be accounted for by models of semantic representation.

In the recent work of McRae and colleagues (e.g., Cree $\&$ McRae, 2003), features were classified by sensory modality and motor considerations. In contrast, in highdimensional models, such as the language-based global co-occurrence models (e.g., Burgess \& Lund, 2000), the meaning units are abstract and amodal. It has been argued that the latter type of model is not in opposition to featurebased models; in fact, Buchanan, Westbury, and Burgess (2001) argued that the semantic system could involve both types of representation.

Several researchers have, however, criticized the abstract amodal approach taken in high-dimensional models as ungrounded (Barsalou, 1999; Glenberg, 1997; Glenberg \& Robertson, 1999, 2000). The argument is that in these models, the symbols are only arbitrarily related to what they signify. Instead, Glenberg and colleagues have proposed a model in which meaning is grounded in bodily activity. This allows meshing of various aspects of meaning, including affordances (relations between objects and bodily abilities), experiences, and goals.

To explain language comprehension, Glenberg and Robertson (1999) proposed the indexical hypothesis. By this hypothesis, sentence processing involves (1) indexing phrases to actual objects or perceptual symbols, (2) using the indexed object or perceptual symbol to derive affordances, and (3) meshing the affordances as a function of sentence syntax. Thus, the meaning of the sentence is captured in large part by the affordances of the referents.

The notion of perceptual symbols was described by Barsalou (1999) in his attempt to address the theoretical divide between models of cognition and models of perception. He noted that whereas perceptual symbols are modal (represented in the same perceptual system that produced them), most cognitive models (e.g., some connectionist models, schemata, etc.) are amodal. As an alternative, he suggested that meaning could be represented by perceptual symbols. These are neural representations in sensory-motor areas, involving several different sensory modalities, as well as proprioception and introspection. Perceptual symbols are componential, and related perceptual symbols are organized by frames so that, for instance, there would be a frame for car containing perceptual symbols from previous category members.

We do not believe that our data provide direct evidence as to the symbolic or nonsymbolic nature of semantic representation. Instead, recall our claim that word meanings are represented in a way that is related to featural information. This allows the possibility that when people activate word meaning they are activating sensory (sounds, perceptions) and conceptual (subordinate category knowledge) information, not amodal symbols (words). Essentially, both symbolic and nonsymbolic models of semantic representation will need to incorporate the notion that, for some concepts, more information is activated than for others and that this facilitates processing. These could be more features, as in many of the connectionist models, or they could be more perceptual symbols, as in Barsalou's (1999) perceptual symbol systems. We do not see this claim as inconsistent with either type of model.

In considering how NOF effects, such as those observed in the present study, could be accounted for by the models proposed by Glenberg (Glenberg \& Robertson, 1999) and 
Barsalou (1999), it seemed possible, at least to us, that there is potential for the effects to be explained. For instance, in the case of the indexical hypothesis (Glenberg \& Robertson, 1999), perhaps the features provided in feature-listing tasks map onto those affordances that are relatively context independent and can be articulated. Perhaps some concepts (high-NOF concepts) invoke more of these affordances and, therefore, enjoy a processing benefit. In the case of the perceptual symbol systems view (Barsalou, 1999), the features provided in feature listing tasks could map onto perceptual symbols. Perceptual symbols are said to be multisensory, proprioceptive, and introspective, and these are similar to the types of features people report in feature listing: perceptual attributes, functional attributes, superordinate category knowledge, and so forth. Within Barsalou's framework, concepts could differ in the number of perceptual symbols that are included in their frames. The concepts with relatively richer frames could be high-NOF words. One would expect a processing benefit for these richer concepts.

Although we believe it may be possible for many models to account for NOF effects in semantic tasks, we do see an advantage to models like those proposed by Plaut and Shallice (1993) and McRae and colleagues (Cree et al., 1999; McRae et al., 1997). The advantage is in specification. Those models offer specific architecture and implementation that allow us to evaluate the extent to which the models are consistent with, for instance, feedback activation effects of the type observed for NOF in LDTs and naming tasks (Pexman et al., 2002). Certain models of semantic representation (e.g., Barsalou, 1999; Glenberg \& Robertson, 2000), as currently described, offer less specificity (at least in the context of word recognition processes), and thus it is more difficult to establish whether those models are able to explain such effects.

An issue we have not addressed in the present work is whether different types of features make different contributions to response latencies. It is possible that certain types of features (e.g., perceptual features) are particularly influential for the meaning activation process and that others (e.g., internal features, functional features) are less influential. It is also possible that all features are equally influential. Furthermore, the influence of these factors may depend on context information and task demands. These possibilities should be considered in future research.

Although we have focused here on NOF effects, there are likely to be many semantic factors that influence computation of word meaning. These may include, for instance, characteristics of semantic neighborhoods (Buchanan et al., 2001; Siakaluk, Buchanan, \& Westbury, 2001; Yates, Locker, \& Simpson, 2001). Given that NOF accounts for a small but significant portion of variance in responses in semantic tasks, our expectation is that future research will show that many different variables influence semantic processing. It seems possible that most of these variables have yet to be identified. Like NOF, those new variables will provide a window on the complex issue of semantic representation.

\section{REFERENCES}

Anderson, J. R. (1983). The architecture of cognition. Cambridge, MA: Harvard University Press.

Balota, D. A., Ferraro, R. F., \& Connor, L. T. (1991). On the early influence of meaning in word recognition: A review of the literature. In P. J. Schwanenflugel (Ed.), The psychology of word meanings (pp. 187221). Hillsdale, NJ: Erlbaum.

Barsalou, L. W. (1999). Perceptual symbol systems. Behavioral \& Brain Sciences, 22, 577-660.

BECKER, C. A. (1980). Semantic context effects in visual word recognition: An analysis of semantic strategies. Memory \& Cognition, 8, 493-512.

Borowsky, R., \& MAsson, M. E. J. (1996). Semantic ambiguity effects in word identification. Journal of Experimental Psychology: Learning, Memory, \& Cognition, 22, 63-85.

Buchanan, L., Westbury, C., \& Burgess, C. (2001). Characterizing semantic space: Neighborhood effects in word recognition. Psychonomic Bulletin \& Review, 8, 531-544.

Burgess, C., \& Lund, K. (2000). The dynamics of meaning in memory. In E. Dietrich \& A. Markman (Eds.), Cognitive dynamics: Conceptual and representational change in humans and machines (pp. 117-156). Hillsdale, NJ: Erlbaum.

Cohen, J., MacWhinney, B., Flatt, M., \& Provost, J. (1993). PsyScope: An interactive graphic system for designing and controlling experiments in the psychology laboratory using Macintosh computers. Behavior Research Methods, Instruments, \& Computers, 25, 257-271.

Collins, A. M., \& LofTus, E. F. (1975). A spreading-activation theory of semantic processing. Psychological Review, 82, 407-428.

Cree, G. S., \& McRae, K. (2003). Analyzing the factors underlying the structure and computation of the meaning of chipmunk, cherry, chisel, cheese, and cello (and many other such concrete nouns). Journal of Experimental Psychology: General, 132, 163-201.

Cree, G. S., McRae, K., \& McNorgan, C. (1999). An attractor model of lexical conceptual processing: Simulating semantic priming. Cognitive Science, 23, 371-414.

Dopkins, S., Morris, R. K., \& RAYner, K. (1992). Lexical ambiguity and eye fixations in reading: A test of competing models of lexical ambiguity resolution. Journal of Memory \& Language, 31, 461-476.

Forster, K. I. (1976). Accessing the mental lexicon. In R. J. Wales \& E. Walker (Eds.), New approaches to language mechanisms (pp. 257287). Amsterdam: North-Holland.

Forster, K. I. (1994). Computational modeling and elementary process analysis in visual word recognition. Journal of Experimental Psychology: Human Perception \& Performance, 20, 1292-1310.

Glenberg, A. (1997). What memory is for. Behavioral \& Brain Sciences, 20, 1-55.

Glenberg, A., \& Robertson, D. A. (1999). Indexical understanding of instructions. Discourse Processes, 28, 1-26.

Glenberg, A., \& Robertson, D. A. (2000). Symbol grounding and meaning: A comparison of high-dimensional and embodied theories of meaning. Journal of Memory \& Language, 43, 379-401.

Hino, Y., \& LuPKer, S. J. (1996). Effects of polysemy in lexical decision and naming: An alternative to lexical access accounts. Journal of Experimental Psychology: Human Perception \& Performance, 22, 1331-1356.

Hino, Y., Lupker, S. J., \& Pexman, P. M. (2002). Ambiguity and synonymy effects in lexical decision, naming, and semantic categorization tasks: Interactions between orthography, phonology, and semantics. Journal of Experimental Psychology: Learning, Memory, \& Cognition, 28, 686-713.

Hinton, G. E., \& Shallice, T. (1991). Lesioning an attractor network: Investigations of acquired dyslexia. Psychological Review, 98, 74-95.

Holcomb, P. J., Kounios, J., Anderson, J. E., \& West, W. C. (1999). Dual-coding, context-availability, and concreteness effects in sentence comprehension: An electrophysiological investigation. Journal of Experimental Psychology: Learning, Memory, \& Cognition, 25, 721-742.

JoNES, G. V. (1985). Deep dyslexia, imageability, and ease of predication. Brain \& Language, 24, 1-19.

Kawamoto, A. H. (1993). Nonlinear dynamics in the resolution of lexical ambiguity: A parallel distributed processing account. Journal of Memory \& Language, 32, 474-516. 
Kellas, G., Paul, S. T., Martin, M., \& Simpson, G. B. (1991). Contextual feature activation and meaning access. In G. B. Simpson (Ed.), Understanding word and sentence (pp.47-71). Amsterdam: Elsevier, North-Holland.

Kellas, G., \& VU, H. (1999). Strength of context does modulate the subordinate bias effect: A reply to Binder and Rayner. Psychonomic Bulletin \& Review, 6, 511-517.

KuČERA, H., \& FrANCIS, W. (1967). Computationalanalysis of presentday American English. Providence, RI: Brown University Press.

Martin, C., Vu, H., Kellas, G., \& Metcalf, K. (1999). Strength of discourse context as a determinant of the subordinate bias effect. Quarterly Journal of Experimental Psychology, 52A, 813-839.

MAsson, M. E. J. (1995). A distributed memory model of semantic priming. Journal of Experimental Psychology: Learning, Memory, \& Cognition, 21, 3-23.

McClelland, J. L., \& Rumelhart, D. E. (1981). An interactive activation model of context effects in letter perception: Pt. 1. An account of basic findings. Psychological Review, 88, 375-407.

McRae, K., de SA, V. R. \& Seidenberg, M. S. (1997). On the nature and scope of featural representations of word meaning. Journal of Experimental Psychology: General, 126, 99-130.

Medin, D. L. (1989). Concepts and conceptual structure. American Psychologist, 44, 1469-1481.

Morton, J. (1969). Interaction of information in word recognition. Psychological Review, 76, 165-178.

OHLsson, S. (2000). Localist models are already here. Behavioral \& Brain Sciences, 23, 486-487.

Paap, K. R., Newsome, S. L., McDonald, J. E., \& Schvaneveldt, R. W. (1982). An activation-verification model for letter and word recognition: The word-superiority effect. Psychological Review, 89, 573-594.

PAGE, M. (2000). Connectionist modeling in psychology: A localist manifesto. Behavioral \& Brain Sciences, 23, 443-512.

Pecher, D. (2001). Perception is a two-way junction: Feedback semantics in word recognition. Psychonomic Bulletin \& Review, 8, 545-551.

Pexman, P. M., \& LupKer, S. J. (1999). Ambiguity and visual word recognition: Can feedback explain both homophone and polysemy effects? Canadian Journal of Experimental Psychology, 53, 323334.

Pexman, P. M., Lupker, S. J., \& Hino, Y. (2002). The impact of feed- back semantics in visual word recognition: Number-of-features effects in lexical decision and naming tasks. Psychonomic Bulletin \& Review, 9, 542-549.

Pexman, P. M., Lupker, S. J., \& Jared, D. (2001). Homophone effects in lexical decision. Journal of Experimental Psychology: Learning, Memory, \& Cognition, 27, 139-156.

Plaut, D. C. (1997). Structure and function in the lexical system: Insights from distributed models of word reading and lexical decision. Language \& Cognitive Processes, 12, 765-805.

Plaut, D. C., \& McClelland, J. L. (2000). Stipulating versus discovering representations. Behavioral \& Brain Sciences, 23, 489-491.

Plaut, D. C., McClelland, J. L., Seidenberg,M. S., \& Patterson, K. (1996). Understanding normal and impaired word reading: Computational principles in quasi-regular domains. Psychological Review, 103, 56-115.

Plaut, D. C., \& Shallice, T. (1993). Deep dyslexia: A case study of connectionist neuropsychology. Cognitive Neuropsychology, 10, 377-500.

RAYNer, K., Binder, K., \& Duffy, S. A. (1999). Contextual strength and the subordinate bias effect: Comment on Martin, Vu, Kellas, and Metcalf. Quarterly Journal of Experimental Psychology, 52A, 841-852.

Schwanenflugel,P., \& Stowe, R. W. (1989). Context availability and the processing of abstract and concrete words in sentences. Reading Research Quarterly, 24, 114-126.

Seidenberg, M. S., \& McClelland, J. L. (1989). A distributed, developmental model of word recognition and naming. Psychological Review, 96, 523-568.

Siakaluk, P. D., Buchanan, L., \& West bury, C. (2001, November). Effects of semantic distance in visual word recognition. Poster presented at the 42nd Annual Meeting of the Psychonomic Society, Orlando, FL.

Van Orden, G. C., Pennington, B. F., \& Stone, G. O. (1990). Word identification in reading and the promise of subsymbolic psycholinguistics. Psychological Review, 97, 488-522.

Vu, H., \& Kellas, G. (1999). Contextual strength and the subordinate bias effect: Reply to Rayner, Binder, and Duffy. Quarterly Journal of Experimental Psychology, 52A, 853-855.

Yates, M., Locker, L., \& Simpson, G. B. (2001, November). Investigating the interaction of semantics and phonology in visual word recognition. Poster presented at the 42nd Annual Meeting of the Psychonomic Society, Orlando, FL. 
APPENDIX

\begin{tabular}{|c|c|}
\hline Low NOF & High NOF \\
\hline \multicolumn{2}{|c|}{ Target Words Presented in Experiment 1} \\
\hline airplane & apple \\
\hline broccoli & bike \\
\hline catapult & boots \\
\hline cherry & bra \\
\hline closet & cat \\
\hline corn & coconut \\
\hline crayon & couch \\
\hline crow & dolphin \\
\hline cupboard & fawn \\
\hline curtains & freezer \\
\hline dresser & fridge \\
\hline hawk & garlic \\
\hline lime & goat \\
\hline pillow & grapefruit \\
\hline pliers & lion \\
\hline pumpkin & mouse \\
\hline sandpaper & ostrich \\
\hline scooter & pants \\
\hline shelves & pistol \\
\hline slippers & potato \\
\hline stone & screws \\
\hline stove & sheep \\
\hline truck & spoon \\
\hline yam & tiger \\
\hline \multicolumn{2}{|c|}{ Target Words Presented in Experiment 3} \\
\hline nightingale & canary \\
\hline oriole & seagull \\
\hline pheasant & parakeet \\
\hline dove & swan \\
\hline finch & budgie \\
\hline partridge & robin \\
\hline flamingo & penguin \\
\hline blackbird & rooster \\
\hline emu & turkey \\
\hline starling & vulture \\
\hline crow & ostrich \\
\hline hawk & duck \\
\hline
\end{tabular}

Note-NOF, number of features.

(Manuscript received April 22, 2002;

revision accepted for publication April 24, 2003.) 